\title{
Regenerativna poljoprivreda
}

\section{Sažetak}

Temeljne postavke i prakse na kojima počiva konvencionalna i integrirana poljoprivredna proizvodnja poput intenzivne obrade tla, uzgoja u monokulturi, upotrebe mineralnih gnojiva, navodnjavanje, zaštita bilja kemijskim sredstvima, manipulacija biljnim i životinjskim genomima te 'industrijska' proizvodnja životinja, među glavnim su onečišćivačima biosfere kao i proizvođačima stakleničkih plinova. Te su prakse kroz duže razdoblje neodržive i štetne. Problematika kojom se bavi regenerativna poljoprivreda je sekvestracija atmosferskog ugljika u tlo i biomasu, povećanje bioraznolikosti proizvodnih agroekosustava, povećanje $i$ održavanje plodnosti tla te uspostavljanje, održavanje i upravljanje ciklusima kruženja hraniva, vode i organske tvari tla. Regenerativna poljoprivreda nadogradnja je ekološke poljoprivrede i temelji se na znanstvenim i primijenjenim istraživanjima.

Ključne riječi: bioraznolikost, diverzifikacija, održiva proizvodnja hrane, regenerativna poljoprivreda

\section{Uvod}

Regenerativna poljoprivreda sustav je poljoprivrednih načela i praksi koje povećavaju bioraznolikost, obogaćuju tlo, popravljaju vodne režime i poboljšavaju ekosustav. Regenerativna poljoprivreda ima za cilj provođenje sekvestracije ugljika imajući tako suprotan učinak od globalnih trendova atmosferske akumulacije. $U$ isto vrijeme, utječe na povećane urode, otpornost klimatskoj nestabilnosti, bolje zdravlje i vitalnost poljoprivrednika i lokalnih zajednica. Sustav počiva na desetljećima znanstvenih i primijenjenih istraživanja globalnih zajednica koje proučavaju ekološku poljoprivredu, agroekologiju, holističko upravljanje i agrošumarstvo.

Regenerativna poljoprivreda kao pojam u Republici Hrvatskoj praktički ne postoji niti se u zadovoljavajućem obimu spominje u domaćoj stručnoj ili znanstvenoj literaturi, međutim naziv u svijetu postoji već oko tridesetak godina, a danas postaje sve aktualniji i dobiva na značenju, kako u stručnim krugovima, tako i u javnoj sferi.

\section{Načelaregenerativne poljoprivrede}

Načela, koncepti i strategije regenerativne poljoprivrede orijentirani su pružanju okvira za dizajniranje održivih agroekosustava, ona nisu 'recept' za upravljanje ili stvaranje točno određenog agroekosustava. Usprkos tome, načela regenerativne poljoprivrede sugeriraju generalne značajke i elemente održivog sustava proizvodnje hrane.

Održivost kao okvir za kritičku analizu 'industrijske' poljoprivrede i za razvoj potencijalnih alternativa ima veliku slabost, a to je što u potpunosti ovisi o hipotetskoj budućnosti. Prozvati praksu ili sustav neodrživim u biti je isto što i tvrditi da sustav nije dobar, jer neće trajati. Održivost nikada ne može biti demonstrirana u sadašnjosti, nego se njezin dokaz uvijek nalazi izvan dosega, u budućnosti, iako određeni sustav u sadašnjosti proizvodi ozbiljne negativne učinke (Velten i sur., 2015). Sustav proizvodnje hrane koji bi bio održiv trebao bi imati sljedeće zna-

1 
čajke: postojanje minimalnih negativnih učinaka na okoliš i otpuštanje zanemarivih toksičnih supstanci u atmosferu, vodu i podzemnu vodu; minimalnu proizvodnju stakleničkih plinova te bi trebao ublažavati klimatske promjene koristeći sustave proizvodnje kao rezervoare ugljika; očuvanje i izgradnju plodnosti tla, prevenciju erozije tla i održanje zdravlja tla; upotrebu vode na način da se vodonosnicima omogući punjenje i da se potrebe okoliša i ljudi za vodom namire; oslanjanje većinom samo na resurse koji postoje na agroekosustavu, zajednice bi trebale koristi kruženje hraniva umjesto njihovog unosa u agroekosustav. Zahtjeva se povećano znanje o ekologiji; rad na očuvanju i povećavanju bioraznolikosti u agroekosustavima; garancija jednakosti u pristupu primjerenim poljoprivrednim praksama, znanju i tehnologijama; eliminacija gladi te osiguranje hranidbene sigurnosti u kulturološki prihvatljivim okvirima; eliminacija socijalne, ekonomske i političke nepravde iz sustava proizvodnje hrane. Svaka od ovih značajki održivog sustava može biti ispitana u sadašnjosti i svaka od njih uključuje neoborive dobrobiti za ljude i za ekosustave (Velten i sur., 2015).

\section{Smanjena obrada i održivo korištenje tla}

$U$ regenerativnoj poljoprivredi primjenjuje se smanjena ili konzervacijska obrada tla koja se generalno odnosi na zadržavanje pokrova na površini tla koji se sastoji od posliježetvenih ostataka sa svrhom smanjivanja obrade tla ili njezinog potpunog dokidanja. Međutim, s obzirom na regionalne, tehničke, ekonomske i institucionalne različitosti, pojam 'konzervacijska obrada tla' ima različito značenje u različitim dijelovima svijeta. Centar za informiranje o konzervacijskoj tehnologiji u SAD-u razvio je prvi široko prihvaćenu definiciju konzervacijske obrade tla kao: 'Bilo koji sustav obrade tla ili sadnje koji pokriva najmanje 30\% površine tla s ostacima usjeva, nakon sadnje, s ciljem smanjivanja erozije vodom' (Carter, 2005). Mannering i Fenster (1983) naglašavaju da je zajednička značajka svake konzervacijske obrade tla njezin potencijal da umanji gubitak tla i vode u odnosu na uobičajenu obradu tla. Slijedom toga, konzervacijska obrada tla može se interpretirati kao bilo koji sustav koji pozitivno utječe na prinos dok $u$ isto vrijeme održava plodnost tla, umanjuje gubitak tla i hraniva i smanjuje utrošak energije odnosno goriva.

Višegodišnji utjecaj konzervacijske obrade tla na značajke agroekosustava, u semiaridnim i semihumidnim područjima u sustavima proizvodnje bez navodnjavanja, promatrali su mnogi autori u tridesetogodišnjem razdoblju. Tako su Bravo i sur. (2007) utvrdili nekoliko pozitivnih učinaka konzervacijske obrade tla s obzirom na održivo korištenje poljoprivrednih površina:

(1) ekonomsku dobrobit, tj. smanjeno ulaganje rada, energije, troškova mehanizacije i vremena, (2) pozitivni učinci na kontrolu erozije tla te očuvanje vode i tla, (3) povećanje postotka organske tvari tla. Sadržaj i kvaliteta organske tvari u tlu (SOM) utječu na mnoge funkcije tla koje se odnose na zdravlje tla, kao što je zadržavanje vlage, infiltracija vode, te zdravlje biljaka. Organski ostaci koji se ostavljaju na polju (ostaci usjeva, pokrovni usjevi i organski otpad) mogu utjecati na patogene i bolesti koje se prenose u tlo, što je kulturna praksa koja može utjecati na dostupnost biljnih hraniva (Stone i sur., 2004). Pokazalo se da postupci kao što su dodavanje treseta, zelenih gnojiva i stajskog gnoja stvaraju supresivne uvjete u tlu u kojima patogeni ne uspijevaju i zbog toga ne utječu na biljni usjev. Pokazalo se da se dodavanjem treseta potiskuje bolest uzrokovana s Pythium spp. (Hu i sur, 1997). Također, pokazalo se da se dodavanjem različitih organskih ostataka smanjuje trulež korijena brojnih vrsta (Hoitink i sur., 1977, Hu i sur., 1997). Stoga hranjive tvari mogu utjecati na učestalost bolesti povećavajući otpornost biljaka, poboljšavajući rast biljaka (omogućujući biljci da izbjegne bolesti) i utječući na okoliš patogena. 


\section{Bioraznolikost kao višefunkcionalna značajka agroekosustava}

U SAD-u, u Kaliforniji, postoji više mješavina sjemena s imenima poput 'Mješavina za dobre kukce' i 'Mješavina za insektarij', koje su dostupne uzgajivačima za povećanje biljne i životinjske biološke raznolikosti (Bugg i Waddington, 1994). U Švicarskoj su na tržištu dostupne sjemenske mješavine 'korova' (Nentwig i sur., 1998). Željeni učinak je suzbijanje štetočina putem povećanja populacija (ili barem djelotvornosti) grabežljivaca i parazitoida. Važno je napomenuti da povećanje biološke raznolikosti ne jamči suzbijanje štetočina (Van Emden i Williams, 1974; Andow, 1991; Gurr i sur., 1998). Razumijevanje mehanizama kojima bi biološka raznolikost mogla pomoći upravljanju štetočinama veoma je važno.

Andow (1991) je otkrio da je gustoća prirodnih neprijatelja bila veća u polikulturnim nasadima nego u monokulturama, međutim, samo nešto više od polovice od 287 vrsta biljnih štetočina bilo je u manjoj mjeri zastupljeno u polikulturama. Jedan od razloga za ovaj nekonzistentan učinak pojačane biljne bioraznolikosti je da se učinci različitih vrsta biljaka na prirodne neprijatelje mogu značajno razlikovati (Nentwig, 1992; Colley i Luna, 2000). Mogu postojati i učinci na drugim trofičkim razinama. Na primjer, biljke mogu osigurati izvore koji favoriziraju štetočine (Baggen i Gurr, 1998) ili članove četvrtog trofičkog nivoa koji bi tada mogli napasti prirodne neprijatelje štetočina (Stephens i sur., 1998). Bez obzira na te potencijalne probleme, postoji mnogo uspješnih načina na koji se biološka raznolikost može koristiti se u agroekosustavima u korist prirodnih neprijatelja, suzbijanju štetočina i, u nekim slučajevima, smanjenju šteta na usjevima (Landis i sur., 2000). Potpuno prepoznavanje višestruko funkcionalne poljoprivredne bioraznolikosti može poslužiti za poticanje odgovarajućih društvenih promjena i posljedično usvajanje primjerenih praksi od strane poljoprivrednika.

\section{'Korovi' na proizvodnoj površini}

Druga važna karakteristika industrijske poljoprivrede je kontrola korova, najčešće upotrebom herbicida. Uklanjanje korova može biti antagonistično prema upravljanju štetočinama. Često ti 'ne-usjevi' pridonose efektu hipoteze koncentracije resursa, mogu dati prednost prirodnim neprijateljima pružajući im izvor alternativne, ne-domaćinske prehrane, kao što su pelud i nektar te također podržavaju alternativne domaćine ili plijen i pružaju zaklon ili blažu mikroklimu. Ponovnim uvođenjem određenih korova na načine koji su agronomski prihvatljivi za poljoprivrednike, moguće je obnoviti neke od usluga ekosustava koje ti korovi pružaju prirodnim neprijateljima (Nentwig i sur., 1998). Alternativni pristup je suzdržati se djelomično (u konvencionalnom uzgoju) ili u potpunosti (u regenerativnom uzgoju) od primjene herbicida $u$ usjevu i omogućiti rast postojeće 'korovske' zajednice.

'Banke kukaca' odnosno niski grebeni zasijani višegodišnjim travama koje formiraju busene koriste se u britanskim i kopnenim europskim ratarskim kulturama više od desetljeća te na taj način osiguravaju prezimljavanje prirodnih neprijatelja lisnih uši (Thomas i sur., 1991; Thomas i Goulson, 2000). 'Banke kukaca' stvaraju veliku gustoću populacija polifagnih predatornih kukaca. Istraživački radovi pokazali su da takvi prirodni neprijatelji mogu smanjiti gustoću lisnih ušiju užitaricama (Chiverton, 1986; Winderisur., 1988; Winder, 1990).

Veća razina složenosti u diverzifikaciji može se očitovati napuštanjem monokulture i uvođenjem međuredne sadnje jednog ili više dodatnih vrsta usjeva koji se uzgajaju na istoj proizvodnoj površini. Diverzifikacija može poprimiti različite forme i razine kompleksnosti: od uključivanja diskretnog područja sekundarnog usjeva do složenih prostornih i/ili vremenskih uzoraka polikulturnog uzgoja. Diverzifikacija agroekosustava uklanja ili smanjuje negativne aspekte suvremene industrijske poljoprivrede. Neki od tih negativnih aspekata su uklanjanje ili degradacija staništa koja nisu dio proizvodne površine (kao što su živice, šume i priobalna vegetacija); korištenje monokultura; potpuno uklanjanje korova unutar i oko usjeva; velike proizvodne površine i operacije obrade tla različitih stupnjeva intenziteta (Jepson, 1989 i Dent, 1995). 
U slučajevima u kojima je poljoprivredna bioraznolikost smanjila gustoću štetočina, moguće je smanjiti primjenu kemijskih odnosno bioloških pesticida na konvencionalnom odnosno ekološkom gospodarstvu. Povećanje bioraznolikosti može imati cijeli spektar koristi, od kojih je najneposrednija financijska korist. Vjerojatno najdetaljnija financijska analiza povezanih koristi i troškova s uvođenjem različitosti za suzbijanje štetnika je ona Thomasa i sur. (1991). Troškovi uspostave banke kukaca u polju pšenice od 20 ha, s obzirom na gubitak prinosa na toj površini po izračunu stoje oko 130 USD/ha. Vrijednost održavanja gustoće štetočina lisnih uši ispod ekonomskog praga štetnosti procijenjena je na 450 USD/ha, a vrijednost izbjegavanja $5 \%$-tne infestacije lisnih ušiju zbog gubitka prinosa bio bi 1000 USD/ha. Takve brojke ilustriraju potencijal značajnih ekonomskih koristi od povećanja biološke raznolikosti. Moguće su dodatne prednosti kada se smanjuje unos pesticida (u integriranom sustavu uzgoja), ili kada je ona potpuno uklonjena (osim bioloških) (kao u organskoj i regenerativnoj poljoprivredi). Za proizvode proizvedene u takvim sustavima mogu se postići premijske cijene (Govindasamy i Italia, 1997) ili se tržišni udio može povećati zbog percipirane koristi od strane potrošača.

\section{Voćarstvo i regenerativna poljoprivreda}

Voćarstvo prema načelima regenerativne poljoprivrede bi trebalo doživjeti korijenite promjene kao što su: diverzifikacija proizvodnje, smanjenje odnosno prestanak ovisnosti o vanjskim inputima, upravljanje vodama koristeći neki od sustava (dizajn ključnih linija), smanjena obrade tla ili njen izostanak, uključivanje životinja u voćarske sustave, agrošumarstvo, upotreba starih sorti i/ili otpornijih novijih sorti, gradnju pojaseva živica i pojaseva za stanište kukcima te upotreba pokrovnih usjeva. Potrebna bi bila diverzifikacija između sorata, dakle sadnja u istom sustavu uzgoja, ali više sorata, jer i raznolikost unutar jedne vrste može pomoći u biljnoj zaštiti (Peacock i Herrick, 2000). Umjesto česte obrade međurednih prostora u voćnjacima, sjetva jednogodišnjih ili višegodišnjih mješavina sjemena korisnog bilja koje može imati razne funkcije poput indirektne zaštite bilja pružanjem staništa određenim korisnim kukcima, ili kao nasad koji će 'maskirati' miris uzgajane kulture te odbijati štetnike ili pak služiti kao 'lovni' usjev (Trembath, 1993). Međuredna sjetva može imati i ulogu zelene gnojidbe ili pak ulogu proizvodnje drugog usjeva, npr. ljekovitog ili aromatičnog bilja (Pereira i sur., 2015).Voćarska praksa može se diverzificirati na način da se uvede više kultura u sadnju, jezgričavih, koštičavih, jagodastih i lupinastih vrsta te je poželjno sadnice mikorizirati zbog povećanja kapaciteta za usvajanje hraniva (Ortas, 2018).

Diverzifikacija koju postižemo na proizvodnoj razini ne donosi samo otpornost biljnih organizama na stres nego donosi i otpornost gospodarstva na tržišni stres (Lancaster i Torres, 2019).

\section{Zaključak}

Konvencionalna poljoprivreda velikim je dijelom sudjelovala u stvaranju problema koji postaju svakim danom sve vidljiviji: klimatskim, okolišnim i javno-zdravstvenim. Prakse konvencionalne poljoprivrede s vremenom dovode do degradacije proizvodnih tala i do gubitka ili degradacije glavnih čimbenika proizvodnje. Regenerativna poljoprivreda nudi rješenje za velik dio tih problema integrirajući prakse, po uzoru na prirodne sustave, koje su komplementarne jedna drugoj, a zajedno dovode do sustava proizvodnje koji je otporniji na okolišni i tržišni stres, sustava koji pomaže u rješavanju viška stakleničkih plinova u atmosferi, povećava bioraznolikost, a pritom je profitabilan. Nakon specijalizacije svih grana društva i ispitivanja najmanjih dijelova cjeline novo doba donosi potrebu za integracijom, spajanjem znanja iz različitih područja i vapi za suradnjom kompetentnih stručnjaka koji su spremni sagledati dijelove kao dio jedne, veće cjeline. Ova tema je veoma opširna i zahtjeva zasigurno dodatan angažman i nova istraživanja kako bi mogla biti obrađena u mjeri koju ona svakako zaslužuje. 


\section{Napomena}

Rezultati prezentirani u radu nastali su iz Završnog rada Maria Gracina 'Regenerativna poljoprivreda i voćarstvo', Sveučilišta u Zagrebu Agronomskog fakulteta.

\section{Literatura}

Andow D.A. (1991) Vegetational diversity and arthropod population response. Annual Review of Entomology 36, 561-586.

Baggen L.R., Gurr G. M. (1998) The influence of food on Copidosoma koehleri, and the use of flowering plants as a habitat management tool to enhance biological control of potato moth, Phthorimaea operculella (Lepidoptera: Gelechiidae). Biological Control, 11(1), 9-17. https://doi.org/10.1006/bcon.1997.0566.

Bravo C., Giráldez J.V., González P., Ordóñez R., Perea F. (2007) Long term influence of conservation tillage on chemical properties of surface horizon and legume crops yield in a Vertisol of southern Spain. Soil Sci 172,141-148.

Bugg R. L., Waddington C. (1994) Using cover crops to manage arthropod pests of orchards: a review. Agriculture, Ecosystems and Environment 50 (1), 11-28. https://doi.org/10.1016/0167-8809(94)90121-x

Carter M.R. i McKyes E. (2005). Cultivation and tillage. U: Hillel D., ur. Encyclopedia of Soils in the Environment. Academic Press, Elsevier Ltd. https://doi.org/10.1016/B0-12-348530-4/00514-2

Chiverton P. (1986) Predator density manipulation and its effects on populations of Rhopalosiphum padi (Hom: Aphididae) in spring barley. Annals of Applied Biology 109, 49-60.

Colley M.R., Luna J. M. (2000) Relative attractiveness of potential beneficial insectary plants. Environmental Entomology 29 (5), 1054-1059. https://doi.org/10.1603/0046-225X-29.5.1054

Dent D. (1995) Integrated pest management. Chapman and Hall, London.

Govindasamy R., Italia J. (1997) Consumer response to integrated pest management and organic agriculture: an econometric analysis. Rutgers University Press, New Brunswick, USA. doi:10.22004/ag.econ.36727.

Gurr G. M., van Emden H. F., Wratten S.D. (1998) Habitat manipulation and natural enemy efficiency. U: Barbosa P., ur. Conservation biological control. San Diego: Academic Press.

Hoitink H.A.J., Van Doren D.M., Schmitthenner A.F. (1977) Suppression of Phytophthora cinnamomi in a composted hardwood bark potting medium. Phytopathology 67, 561-565.

Hu S., van Bruggen A.H.C., Wakeman R.J., Grunwald N.J. (1997) Microbial suppression of in vitro growth of Pythium ultimum and disease incidence in relation to soil C and Navailability. Plant Soil 195, 43-52.

Jepson P.C. (1989) The temporal and spatial dynamics of pesticide side-effects on non-target invertebrates. U: Jepson P.C., ur., Pesticides and non-target invertebrates. Intercept Ltd, Andover, Dorset, 95-128.

Lancaster N.A., Torres A.P. (2019). Investigating the Drivers of Farm Diversification Among U.S. Fruit and Vegetable Operations. Sustainability 11(12), 3380. https://doi.org/10.3390/su11123380

Landis D., Wratten S.D., Gurr G. M. (2000). Habitat management for natural enemies. Annu. Rev. Entomol 45:175201 https://doi.org/10.1146/annurev.ento.45.1.175

Mannering J. V., Fenster C. R. (1983) What is conservation tillage? Journal of Soil and Water Conservation 38 (3), 141-143.

Nentwig W. (1992) The promotive effect of weeds in sown strips on beneficial arthropods. Zeitschrift für Pflanzenkrankheiten und Pflanzenschutz 13, 33-40.

Nentwig W., Frank T., Lethmayer C. (1998) Sown weed strips: artificial ecological compensation areas as an important tool in conservation biological control. U: Barbosa P., ur. Conservation biological control. San Diego: Academic Press.

Ortas I. (2018) Role of mycorrhizae on mineral nutrition of fruit tree. Acta Horticulture 1217, 271-284.

Peacock L., Herrick S. (2000) Responses of the willow beetle Phratora vulgatissima to genetically and spatially diverse Salix spp. plantations. Journal of Applied Ecology 37, 821-831. https://doi.org/10.1046/j.1365-2664.2000.00528.x

Pereira, A.L.C., Taques T.C., Valim J.O.S., Madureira A.P., Campos W.G. (2015) The management of bee communities by intercropping with flowering basil (Ocimum basilicum) enhances pollination and yield of bell pepper (Capsicum annuum). Journal of Insect Conservation, 19 (3), 479-486. doi:10.1007/s10841-015-9768-3

Stephens M.J., France C.M., Wratten S.D., Frampton C. (1998) Enhancing biological control of leafrollers (Lepidoptera: Tortricidae) by sowing buckwheat (Fagopyrum esculentum) in an orchard. Journal Biocontrol Science and Technology 8 (4), 547-558. https://doi.org/10.1080/09583159830063

Stone A.G., Scheuerell S.J., Darby M.D. (2004) Suppression of soilborne diseases in field agricultural systems: Organic matter management, cover cropping, and other cultural practices'. U: Magdoff F., Weil R.R., ur., Soil Organic Matter in Sustainable Agriculture, CRC Press, New York.

Thomas M.B., Wratten S.D., Sotherton N.W. (1991) Creation of 'island' habitats in farmland to manipulate populations of beneficial arthropods: predator densities and emigration. Journal of Applied Ecology 28 (3), $906-917$.

Thomas S.R., Goulson D. (2000) The contribution of beetle banks to farmland biodiversity. Aspects of Applied Biology 62, 31-38.

Trembath B.R. (1993) Intercropping for the management of pests and diseases. Field Crops Research 34 (3-4):381405. https://doi.org/10.1016/0378-4290(93)90123-5.

Van Emden H.F.,Williams G.F. (1974) Insect stability and diversity in agro-ecosystems. Annual Review of Entomology $19,455-475$.

Velten S., Leventon J., Jager N., Newig J. (2015) What Is Sustainable Agriculture? A Systematic Review. Susta- inability 7, 7833-7865; doi:10.3390/su7067833

Winder L., Carter N., Wratten S.D. (1988) Assessing the cereal aphid control potential of ground beetles with a simulation model. Proceedings Brighton Crop Protection Conference - Pests and Diseases 3, 1155-1160

Winder L. (1990) Predation of the cereal aphid Sitobion avenae by polyphagous predators on the ground. Ecological Entomology 15, 105-110 https://doi.org/10.1111/j.1365-2311.1990.tb00789.x 


\title{
Regenerative agriculture
}

\begin{abstract}
Basic principles and practices on which conventional and integrated agricultural production is based, such as intensive tillage, monoculture, use of mineral fertilizers, irrigation, plant protection with chemical agents, manipulation of plant and animal genomes and 'industrial' animal production are among the main polluters of the biosphere and greenhouse gas producers. These practices are unsustainable and harmful over prolonged period of time. Regenerative agriculture deals with matters of the sequestration of atmospheric carbon into soil and biomass, increasing the biodiversity of production of agro-ecosystems, increasing and maintaining soil fertility and establishing, maintaining and managing cycles of nutrients, water and soil organic matter. Regenerative agriculture is an upgrade of organic agriculture and it is based on scientific and applied research.

Keywords: biodiversity, diversification, regenerative agriculture, sustainable food production
\end{abstract}

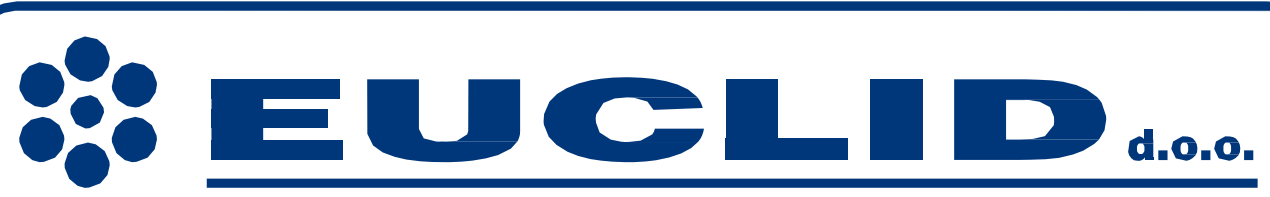

- Sušare za voće, povrće i ljekovito bilje, komorne i tunelske, ukupne površine ladica 2,5 do $300 \mathrm{~m}^{2}$

- $\quad$ Linije za proizvodnju sokova od voća i povrća (mutnih, bistrih igustih) kapaciteta 40 do 500 lit/h

- Generatori octa, za ubrzanu fermentaciju octa

- Tehnološka oprema za pripremu i doradu voća i povrća (uređaji za pranje, istresanje box paleta, rezanje, mljevenje, pasiranje, pasterizaciju, blanširanje, sterilizaciju i dr.)

- $\quad$ Pasirke za odvajanje koštica, kožica i sjemenki iz voća i povrća (šljive, višnje, marelice, breskve, kupine, maline, jagode, mandarine, rajčica i dr.)

- Mlinovi za uzorke tla, za analizu u laboratorijima za tlo

EUCLID d.o.o. za proizvodnju, trgovinu i usluge $\cdot$ VINKOVCI Starčevićeva 4, 32100 Vinkovci, Hrvatska • tel: +385 32331341 GSM: +385 98896707 • e-mail: euclid@euclid.hr · www.euclid.hr 